\section{The Production of the Proof Sovereign}

\section{Robert Matthews*}

Formerly Queen's Assay Master, The Royal Mint, Llantrisant, Pontyclun, United Kingdom
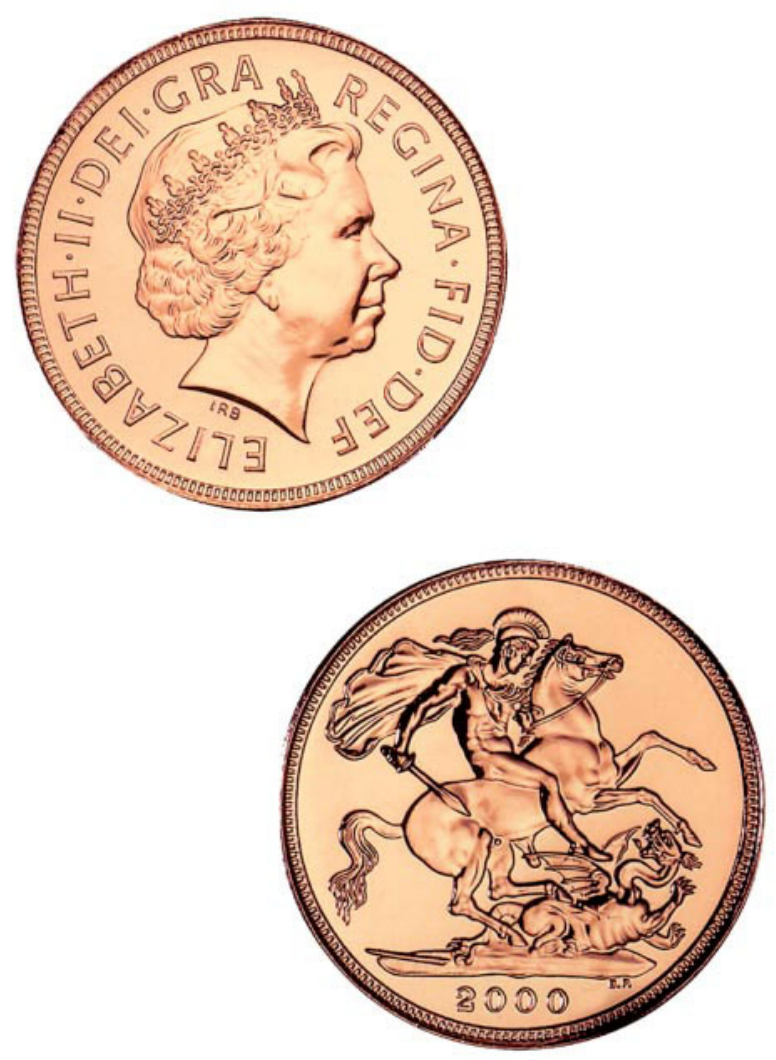

Figure 1

The millennium bullion sovereign

\section{Introduction}

The modern gold sovereign was introduced in 1817. It's size and design have remained very much the same since that time. Similar to all British coinage the sovereign's obverse side, commonly called the heads, contains a likeness of the monarch. The coin's reverse side, commonly called the tails, usually carries a design by Benedetto Pistrucci of St. George fighting the dragon. These can be seen in Figure 1 on a sovereign produced for the Millennium year.

The Royal Mint in London produced large numbers of these sovereigns. Production of sovereigns peaked in 1911 and 1912 when over 30 million sovereigns were produced annually. Since 1917, the UK production of sovereigns has been spasmodic. The highest minting of recent years was just over nine millions coins in 1979. No bullion sovereigns were produced between 1982 and 2000.

These coins were made as bullion sovereigns that is coins whose value depended on their gold content. Whilst Britain was tied to the gold standard this meant the sovereign contained it's face value of gold. Today the bullion value of the coin is of much greater value than its one pound face value.

Sovereigns were also produced in the Royal Mint's branch mints in Australia, Canada, South Africa and India. The last production of sovereigns by a branch mint was by South Africa in 1932. Sovereigns made by one of the branch mints can be identified by a mintmark on the bottom of the obverse side. An example is the $\mathrm{M}$ used to identify coins made at the Melbourne Mint.

Traditionally sets of proof coins have been produced to celebrate the accession of the monarch to the throne These have usually included the proof sovereign. Since 1979, proof sovereigns have been produced every year. A proof coin is one produced with specially prepared coinage blanks and polished dies. It has no damage marks on the coin face and has a bright, highly polished surface. Often the Royal Mint uses a frosted finish on the main design features of its proof coins. This produces a pleasing differentiation between the design surface and the remainder of the coin.

\section{Producing Proof Sovereigns}

Sovereigns are made from a 22 carat gold /copper alloy. 999.9\% gold and the highest grade copper available are used to produce the alloy used in the proof coins. The gold and copper are initially alloyed in a high frequency electrical furnace to ensure proper mixing of the metals. The alloy produced is then melted and continuously cast in an electrical resistance furnace, Figure 2 . This produces two strands of cast bar about $80 \mathrm{~mm}$ wide and $12 \mathrm{~mm}$ deep. This bar is cut into one metre length slabs. 
To remove any minor contamination from the melting, $0.35 \mathrm{~mm}$ is scalped from the surface of each side of the cast slabs. The slabs are then rolled on a breakdown mill to $1 \mathrm{~mm}$ above the required finished gauge. Work hardening means that when a gauge of about $6 \mathrm{~mm}$ is achieved an intermediate anneal is required to soften the gold alloy. This annealing is carried out on a belt annealing furnace under a protective atmosphere of nitrogen.

The final rolling operation is carried out on a finishing mill. The sovereign weight tolerance is very tight, $7.98805 \pm$ $0.01296 \mathrm{~g}$, This requires very careful control at this final rolling stage to ensure the required gauge is achieved, Figure 3. This influences the yield of good coinage blanks obtained and the economics of the whole manufacturing process.

The fillets of gold alloy produced after finish rolling have coinage blanks punched out of them by a conventional bed and punch tool. The blanks are then weighed to ensure they are within the required tolerance. They are then rimmed. This process increases the thickness at the blank's edge by squeezing the blank between a rotating and a fixed tool. The

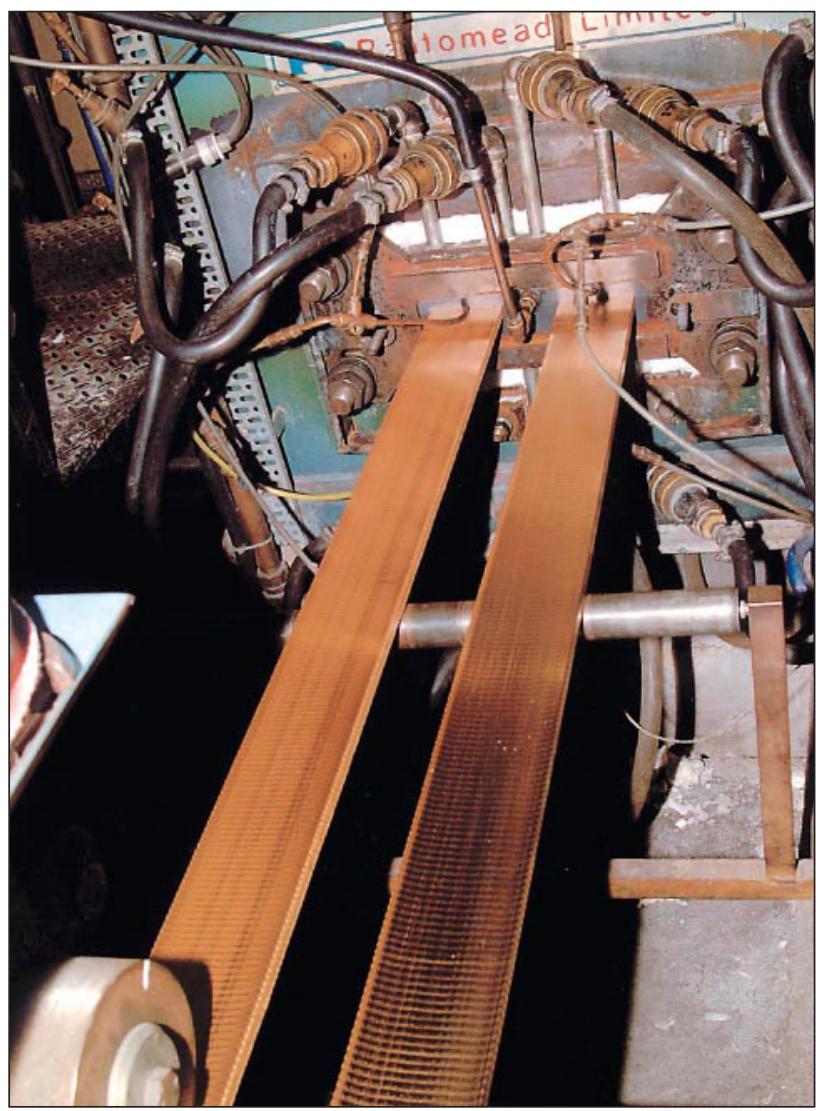

Figure 2

Cast 22 carat gold leaving the continuous casting furnace

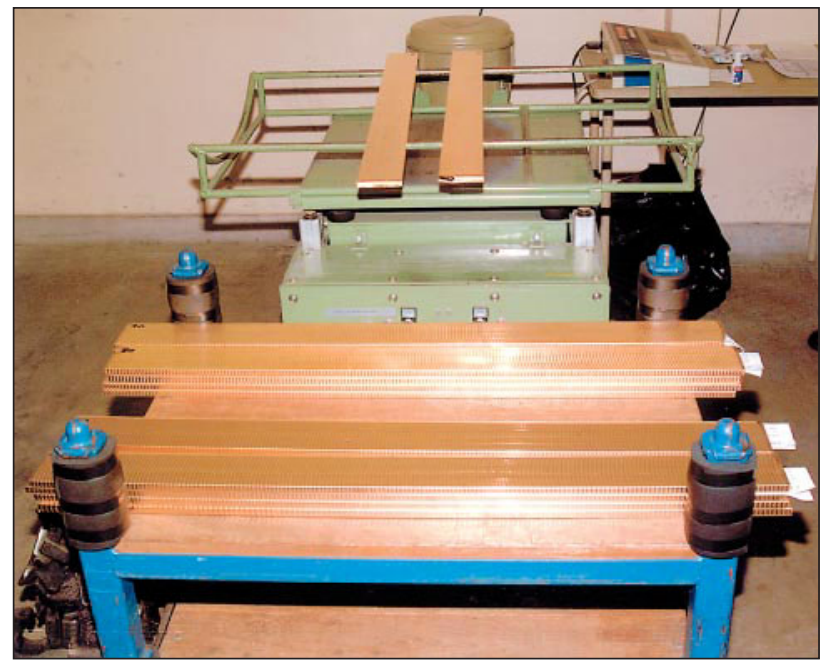

Figure 3

One metre length gold slabs awaiting check weighing
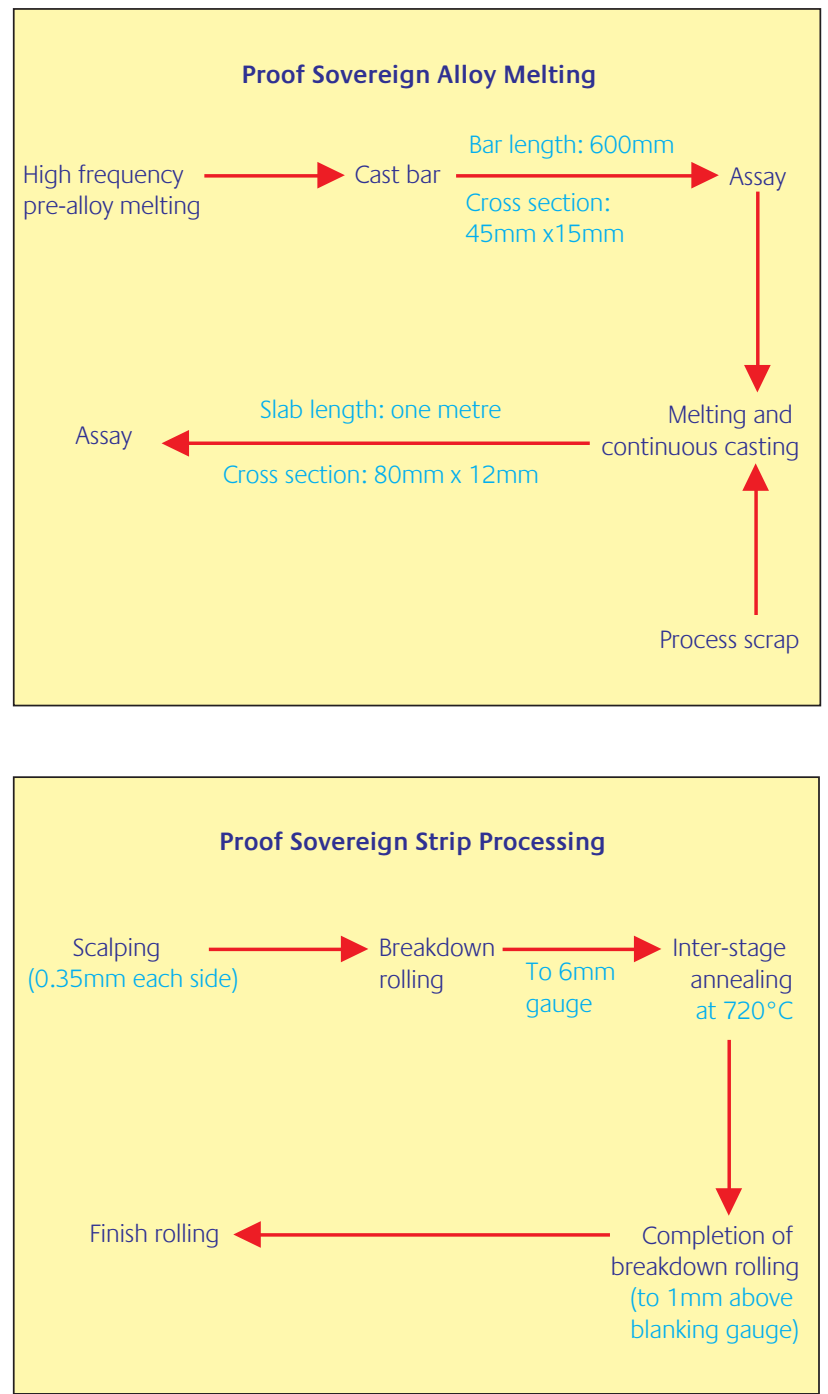


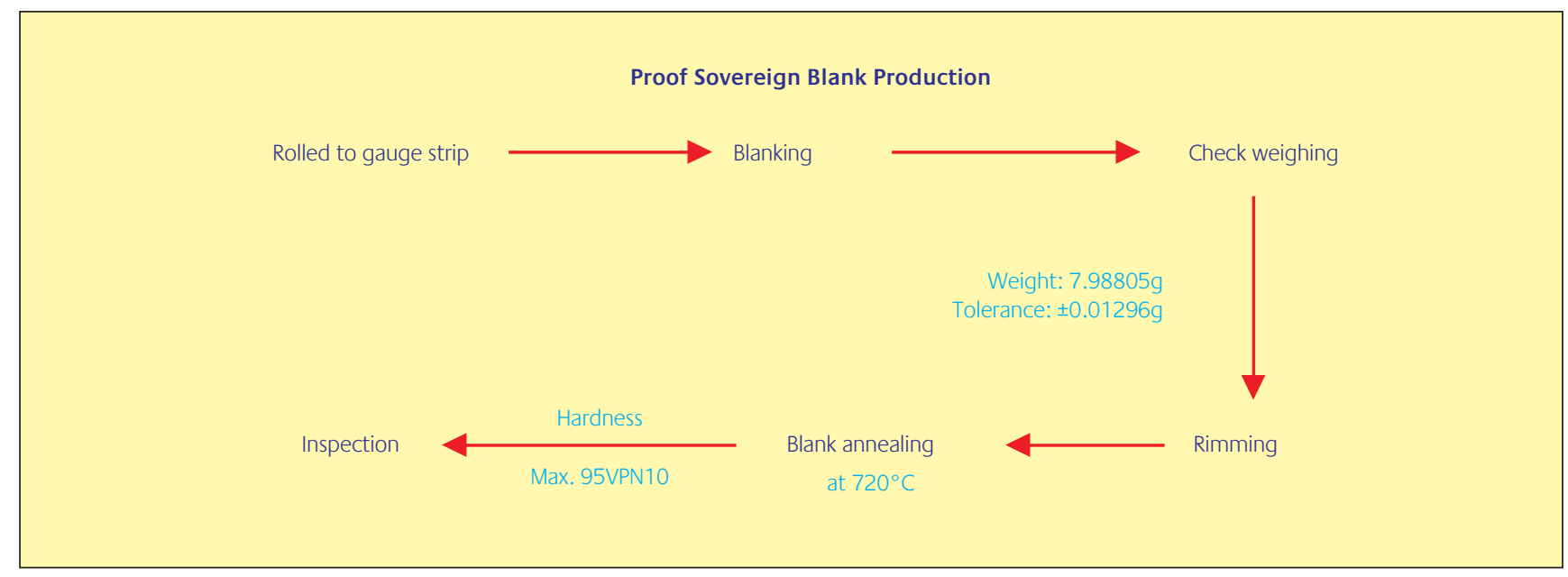

rim on the blank reduces the pressure required during coining. The blanks are then annealed to soften them for coining.

The annealed blanks are then cleaned and polished on a high energy, centrifugal blank finisher. In this finisher, the blanks are burnished between a media of stainless steel balls. Special burnishing soaps are used in this finisher to lubricate the blank for coining.

The blanks are struck between two steel dies in a coinage press to impart the required design onto the coin. During this striking operation, the blank is held in a circular collar. The sovereign collar contains a large number of vertical grooves and this transfers to the coin, producing a milled edge. The coinage dies are specially polished and coated to produce a bright, smooth coin. Finally, the coin is packed into the appropriate coin case. The proof coin press shop is shown in Figure 4.

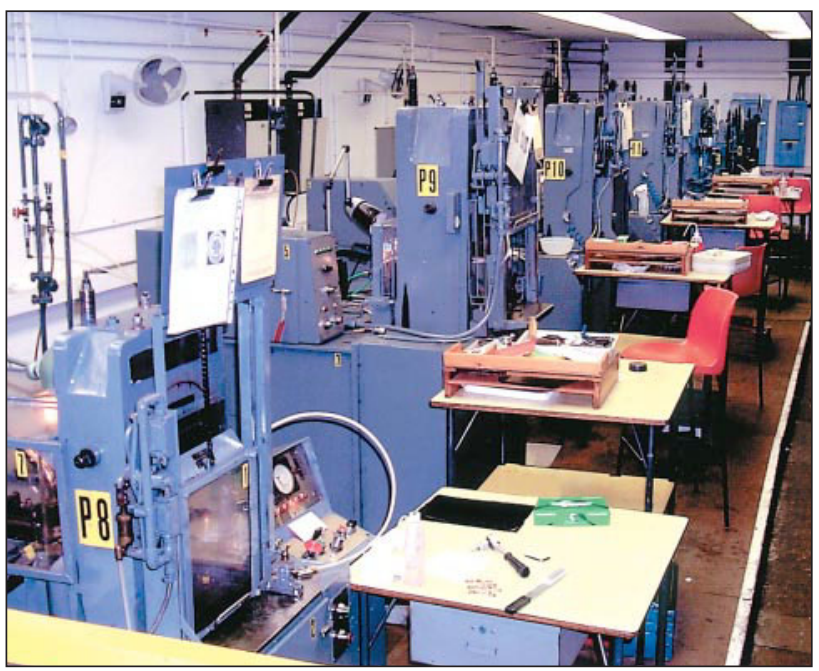

Figure 4

The proof coin press shop

\section{Quality Control}

The Royal Mint operates a total quality system where the product quality is the responsibility of all staff. Staff are required to continually monitor the quality of all the work they produce. This is supplemented by formal inspection and assaying at a number of points in the production cycle. The alloy is assayed after pre-alloying, after continuously casting and after coining. The piece weight is checked after blanking and coining. Finally, inspection for visual defects is carried out after annealing and final coining.

\section{Concluding Remarks}

The proof sovereign carries on the tradition of a coin over one hundred and eighty years old. It is produced by a combination of modern technology and craftsmanship. The Royal Mint believes in its compliance to the very tightest tolerances on composition and weight and its visual beauty it still leads the world.

* now at Robert Matthews Coin Authentication, Bridgend, CF31 5DP 